\title{
STAPLED HEMORRHOIDECTOMY: present status
}

\author{
Antônio LACERDA-FILHO and Rodrigo Gomes da SILVA
}

\begin{abstract}
Aim - To evaluate cost-effectiveness of stapled hemorrhoidectomy comparing its results with conventional technique. Source of data - We retrospectively analyzed the MEDLINE data basis from 2000 to 2004 studying randomized clinical trials which compared pain intensity, recovery period, return to work and occurrence of anal incontinence, in addition to postoperative complications and costs evaluation between stapled and conventional hemorrhoidectomy during different periods of follow-up. Conclusions - Stapled hemorrhoidectomy provides lesser postoperative pain and earlier return to work than conventional hemorrhoidectomy. However, its efficacy could not be determined, since rigorous prospective and randomized clinical trials with long-term follow-up periods and large size samples are not available at this time.
\end{abstract}

HEADINGS - Hemorrhoids, surgery. Surgical staplers.

\section{INTRODUCTION}

Hemorrhoidal plexus are nonpathological cushions of vascular and connective tissues found in anal canal which is regarded to contribute to anal continence. Hemorrhoidal disease - or hemorrhoids - occurs when symptoms like bleeding, prolapse, discharge or itching are caused by hypertrophy of these cushions. Treatment of hemorrhoidal disease in early stages includes conservative approach alone or in association to rubber band ligation. Other procedures such as infrared photocoagulation, sclerotherapy, lasertherapy or cryotherapy have been also occasionally used.

First choice treatment for symptomatic combined internal and external hemorrhoids is hemorrhoidectomy. Milligan-Morgan and Ferguson techniques are the most performed procedures around the world. In 1993, LONGO et al. (15) described the "stapled hemorrhoidectomy" which is performed by using a specially designed stapling device named as $\mathrm{PPH}^{\circledR}$ (procedure for prolapse and hemorrhoids).

The main advantage of stapled hemorrhoidectomy is supposed to be the occurrence of no - or very low - postoperative pain with brief return to work. Despite the initial very favorable reports, two questions must however be raised: 1 . is this new technique better than conventional hemorrhoidectomy? and 2 . is there a justifiable cost-benefit ratio for the routine use of stapled hemorrhoidectomy?

In 2000, CHEETHAM et al. ${ }^{(3)}$ estimated that 50,000 stapled hemorrhoidectomy operations had already been performed in Europe. Despite that wide acceptance, few randomized studies have been undertaken to assess the advantages of this new procedure (Table 1).

TABLE 1 - Stapled versus conventional hemorrhoidectomy in randomized trials

\begin{tabular}{|c|c|c|c|c|c|c|c|}
\hline Authors & Year & $\mathrm{n}$ & Degree & Pain & Return to work & Incontinence & Follow-up \\
\hline Rowsell et al. ${ }^{(25)}$ & 2000 & 22 & $3^{\text {rd }}$ & Less in SHG & Earlier in SHG & NA & 6 weeks \\
\hline Mehigan et al..$^{(16)}$ & 2000 & 40 & $3^{\text {rd }}$ & Less in SHG & Earlier in SHG & NS & 10 weeks \\
\hline Ho et $\mathrm{al}^{(10)}$ & 2000 & 119 & $4^{\text {th }}$ & Less in SHG & NA & NS & 19 weeks \\
\hline Khalil et al. ${ }^{(12)}$ & 2000 & 40 & $3^{\text {rd }}$ & Less in SHG & NA & NS & 6 months \\
\hline Kirsch et al. ${ }^{(13)}$ & 2001 & 300 & $3^{\text {rd }}$ & Less in SHG & Earlier in SHG & NA & 6 months \\
\hline Ganio et al. ${ }^{(8)}$ & 2001 & 100 & $3^{\text {rd }}$ and $4^{\text {th }}$ & Less in SHG & Earlier in SHG & NS & 16 months \\
\hline Boccasanta et al. ${ }^{(2)}$ & 2001 & 80 & $4^{\text {th }}$ & Less in SHG & Earlier in SHG & NA & 54 weeks \\
\hline Hetzer et al. ${ }^{(9)}$ & 2002 & 40 & $2^{\text {nd }}$ and $3^{\text {rd }}$ & Less in SHG & Earlier in SHG & NS & 12 months \\
\hline Wilson et al. ${ }^{(28)}$ & 2002 & 99 & $3^{\text {rd }}$ & NA & Earlier in SHG & NS & NA \\
\hline Correa-Rovelo et al. ${ }^{(5)}$ & 2002 & 84 & $3^{\text {rd }}$ & Less in SHG & Earlier in SHG & NS & 14 months \\
\hline Kairaluoma et al..$^{(11)}$ & 2003 & 60 & $3^{\text {rd }}$ & Less in SHG & NS & $\mathrm{NA}$ & 12 months \\
\hline Cheetham et al.(4) & 2003 & 31 & $3^{\text {rd }}$ & Less in SHG & NS & NA & 6 months \\
\hline Palimento et al. ${ }^{(19)}$ & 2003 & 52 & $3^{\text {rd }}$ and $4^{\text {th }}$ & Less in SHG & NA & NS & 17.5 months \\
\hline Racalbuto et al..$^{(23)}$ & 2004 & 100 & $3^{\text {rd }}$ and $4^{\text {th }}$ & Less in SHG & Earlier in SHG & NS & 48 months \\
\hline
\end{tabular}

Department of Surgery, Federal University of Minas Gerais School of Medicine, Belo Horizonte, MG, Brazil.

Address for correspondence: Dr. Antônio Lacerda-Filho - Rua Ten. Brito Melo, 1355 - sl. 902 - Santo Agostinho - 30180-150 - Belo Horizonte, MG, Brazil. E-mail: alacerda@ufmg.br 
The rational for stapled hemorrhoidectomy, as suggested by $\mathrm{LONGO}^{(15)}$, is associated to important changes in concepts of surgical treatment of hemorrhoids. Stapled resection of a complete circular strip of mucosa above the dentate line is supposed to lift the hemorrhoidal cushions into the anal canal.

\section{Indications}

Indications for stapled hemorrhoidectomy remain subject of controversy. Conventional hemorrhoidectomy has been regarded to be indicated on third- or fourth-degree hemorrhoids and the same has been proposed for $\mathrm{PPH}^{\mathbb{(}(9,19)}$. Some studies with stapled hemorrhoidectomy have been however included second-degree hemorrhoids ${ }^{(10)}$ or not included fourth-degree disease ${ }^{(13,16,25,28)}$. PERNICE et al. ${ }^{(21)}$ have included only 10 patients fourth-grade in a 10 -year series. HO et al. ${ }^{(10)}$ have not used the classical MilliganMorgan classification of hemorrhoids in a randomized trial. Others have studied only third-degree hemorrhoids in randomized clinical trials $^{(13,28)}$. Furthermore, stapled hemorrhoidectomy has been compared with different techniques of "conventional" hemorrhoidectomy, such as Milligan-Morgan ${ }^{(9,10,13,16,23,25,28)}$, Ferguson ${ }^{(5,12)}$ Whitehead $^{(2)}$ and diathermy techniques ${ }^{(4,10,11)}$, suggesting a possible bias for comparative studies between surgical techniques.

If we agree that stapled hemorrhoidectomy is indicated only for third-degree hemorrhoids - associated or not with mucosal prolapse - what is the proportion of patients who should be offered a rubber band ligation as first choice procedure? According to current literature, results of rubber band ligation have been excellent with $90 \%$ of satisfaction ${ }^{(14)}$. Thus, it may be argued whether indication for rubber band ligation should be replaced by stapled hemorrhoidectomy. In a recent prospective and randomized study, PENG et al. ${ }^{(20)}$ compared results of rubber band ligation and stapled hemorrhoidectomy in patients with grade third and small grade fourth piles. They observed no difference between the two groups in terms of controlling symptomatic prolapse, continence scores, patient satisfaction, or quality of life. Patients who underwent rubber band ligation had more residual bleeding but, in the other hand, had smaller amount of complications related to the procedure as occurred with stapled hemorrhoidectomy. The authors concluded that for those patients who do not want the risk of further intervention procedures, stapled hemorrhoidectomy offers the better chance of a symptomatic cure ${ }^{(20)}$.

\section{Efficacy}

Some series have shown that stapled hemorrhoidectomy is as efficient as conventional procedures. BOCCASANTA et al. ${ }^{(2)}$ have studied 80 patients with fourth-degree hemorrhoids who were randomly assigned to undergo stapled hemorrhoidectomy $(\mathrm{n}=40)$ or conventional technique $(\mathrm{n}=40)$ with mean follow-up of 54 weeks. The authors have confirmed that both operations are effective in the treatment of advanced hemorrhoidal disease. GANIO et al. ${ }^{(8)}$ in a mean follow-up of 16 months observed that self-reported prolapse was more common in the stapled hemorrhoidectomy group. More recently, RACALBUTO et al. ${ }^{(23)}$ showed, in the long-term follow-up at 48 months, that stapled hemorrhoidectomy was found to control prolapse, discharge, and bleeding, with no stenosis or significant incontinence, in $94 \%$ of cases.
SINGER et al. ${ }^{(26)}$ published the initial experience with stapled hemorrhoidectomy in the United States. Sixty-eight patients underwent surgery by $\mathrm{PPH}^{\circledR}$ technique with a mean followup of 34.3 weeks (range 0-72). In 63 patients, the procedure was considered effective, but 5 patients $(7.4 \%)$ have required further therapy for their hemorrhoids. One patient described a complete recurrence of circumferential prolapse and was treated by an excisional hemorrhoidectomy elsewhere and lost for follow-up. Two patients had bleeding and required excision of hemorrhoidal tissue distal to the staple line, and two others had rubber band ligation for persistent bleeding and prolapse ${ }^{(26)}$. In addition, another eight patients complained of persistent bleeding, prolapse, or itching, and nothing is mentioned about further treatment in these cases.

In 2003, CHEETHAM et al. ${ }^{(4)}$, from the St. Mark's Hospital of London, in a small randomized trial related that, at longterm follow-up, three patients in the stapled group $(n=15)$ developed new symptoms of fecal urgency and anal pain, and three patients required further surgery to remove symptomatic external hemorrhoids after stapled hemorrhoidectomy. In another small randomized study, PALIMENTO et al. ${ }^{(19)}$ related no differences between the stapled group and Milligan-Morgan group concerning episodes of bleeding at long-term follow-up $(13.5 \%$ versus $21.6 \%, P=0.542)$. In a recent wide study in Brazil with one-hundred patients underwent stapled hemorrhoidectomy, NAHAS et al. ${ }^{(18)}$ have also demonstrated that incidence of late reoperations is rather high. Thus, it seems that current follow-up is not long enough to draw definitive conclusions about longterm efficacy of stapled hemorrhoidectomy compared with conventional hemorrhoidectomy.

\section{Postoperative pain}

It has been assumed as a consensus that stapled hemorrhoidectomy is associated with reduced postoperative pain and early return to work when compared with conventional hemorrhoidectomy. Painless postoperative course was the main reason for the widespread use of stapled hemorrhoidectomy in Europe $^{(3)}$. At least 13 recent randomized trials have confirmed such findings (Table 1).

KIRSCH et al. ${ }^{(13)}$ have published a study with 300 patients randomized between Milligan-Morgan or Longo's operation for third-degree hemorrhoids. They found that average pain, use of analgesics and return to work were shorter in the stapled group. Similar results were observed in the American experience with $\mathrm{PPH}^{\circledR(26)}$. HETZER et al. ${ }^{(9)}$ have shown that stapled hemorrhoidectomy technique was associated to a significantly reduced postoperative pain on the first 4 postoperative days, when assessed by visual analog scales. Nevertheless, hospital stay, first bowel movement, patient-assessed symptom control, functional outcome and complications have been similar in patients who undergone stapled or conventional hemorrhoidectomy ${ }^{(16)}$.

\section{Postoperative incontinence}

The insertion of stapler into anal canal has been reported to damage muscle fibers of anal sphincters in low colorectal or coloanal anastomosis. Similar concern has been raised by the insertion of a large diameter anal speculum for the purse 
string suture in stapled hemorrhoidectomy. Recent trials have shown no increased rate of incontinence in patients treated with stapled hemorrhoidectomy (Table 1). Four randomized trials have reported results of anorectal manometry before and after stapled hemorrhoidectomy or conventional techniques ${ }^{(8,10,12,28)}$. HO et al. ${ }^{(10)}$ have reported that minor incontinence was not significantly different in stapled group compared with conventional group. Changes from preoperative anorectal manometry and endoanal ultrasound findings observed in postoperative period at 6 weeks and 3 months were not significantly different between stapled versus conventional groups ${ }^{(10)}$. KHALIL et al. ${ }^{(12)}$ have found that postoperative resting and squeeze pressures were reduced by stapled method at 3 months but normal pressure profile was observed at 6-month evaluation. The frequent presence of muscle fibers in the pathologic specimen does not seem to lead to impaired continence, as pointed out by ESSER et al. ${ }^{(6)}$.

\section{Complications}

The small number of patients included in clinical trials with different end-points seems to be insufficient to determine definitive complication rates. Prophylactic antibiotics have been suggested by MOLLOY and KINGSMORE ${ }^{(17)}$ in a study regarding severe pelvic and retroperitoneal sepsis after stapled hemorrhoidectomy. WONG et al. ${ }^{(29)}$ reported another case of rectal perforation and fecal peritonitis. Recently, PESSAUX et al. ${ }^{(22)}$, in France, reported one more case of pelvic sepsis secondary due to stapled hemorrhoidectomy. Another life-threatening complication was reported by RIPETTI et al. ${ }^{(24)}$, who described a case of rectal perforation, retropneumoperitoneum and pneumomediastinum after a difficult stapling procedure for hemorrhoids. It has been emphasized that severe complications like these suggest caution in the use of this technique, which should be performed by experienced colorectal surgeons who are familiar with the technique and aware of possible complications ${ }^{(24,29)}$.

PERNICE et al. ${ }^{(21)}$ have reported a rate of $17 \%$ of minor bleeding in an uncontrolled study with 56 patients treated by stapled hemorrhoidectomy. According to American experience, intraoperative bleeding from the staple line was seen in nearly $90 \%$ of patients and use of absorbable sutures ${ }^{(26)}$ have been recommended. Moreover, they have reported one case of massive bleeding in the recovery room leading to a surgical revision ${ }^{(26)}$. HETZER et al. ${ }^{(9)}$ have also described severe bleeding after stapled hemorrhoidectomy which required blood transfusion and reoperation. No study has been published so far with particular emphasis in this apparently not uncommon complication of stapled hemorrhoidectomy.
In the unique meta-analysis published on this issue, SUTHERLAND et al. ${ }^{(27)}$ have found only seven randomized clinical trials that provided relevant safety and efficacy outcome information. They concluded that stapled hemorrhoidectomy may be at least as safe as conventional hemorrhoidal techniques but its efficacy compared with conventional surgery could not be determined and more accurate studies with longer follow-up periods and large size samples need to be conducted ${ }^{(27)}$.

\section{Costs}

Another very important issue to be raised is the cost of stapled hemorrhoidectomy. At least three randomized trials have compared the cost between stapled hemorrhoidectomy and conventional surgery. HO et al. ${ }^{(10)}$ have shown that stapled hemorrhoidectomy is more expensive than conventional operation (US\$ 1,283.09 versus US\$ 921.17). Similar findings were reported by KIRSCH et al. ${ }^{(13)}$. In opposition, WILSON et al. ${ }^{(28)}$ have found that stapled hemorrhoidectomy was less expensive, because it had a smaller cost of operating room usage time and hospital stay than open hemorrhoidectomy.

Aspects regarding costs may be particularly relevant in developing countries. More than 25,000 hemorroidectomies were performed in Brazil in 2000 according to official government surgical database ${ }^{(1)}$. Notwithstanding, the use of stapling device for the treatment of hemorrhoids has not been accepted yet by National Health System (SUS), as well as the majority of health insurance companies, due to financial reasons. However, possible shorter length of hospitalization and earlier return to work must also be considered in the overall analysis regarding costs of stapled hemorrhoidectomy, as WILSON et al. ${ }^{(28)}$ have demonstrated.

\section{CONCLUSION}

We can conclude that there are strong evidences that stapled hemorrhoidectomy provides less postoperative pain than conventional procedures as well as an earlier return to work. As suggested by $\mathrm{FAZIO}^{(7)}$, multicentric trials not sponsored by stapler manufactures must investigate its long-term outcome and potential complications in order to define the role of this new technology in the treatment of hemorrhoids.

\section{ACKNOWLEDGEMENT}

The authors thank Dr. Mauro Leite de Souza Pinho for his suggestions on this manuscript.

Lacerda-Filho A, Silva RG. Hemorroidectomia por grampeamento: estado atual. Arq Gastroenterol 2005;42(4):191-4.

RESUMO - Objetivo - Avaliar se a eficácia da técnica de hemoirrodectomia por grampeamento é maior do que a tradicional, assim como analisar a relação custo-benefício antes de seu emprego rotineiro. Fontes de dados - Analisaram-se retrospectivamente, várias publicações mundiais de ensaios randomizados, no período de 2000 a 2004, em que se compararam a intensidade da dor, o tempo de retorno às atividades profissionais, a importância de incontinência fecal e outras complicações no período pós-operatório de grupos de pacientes submetidos a ambas as técnicas, durante diferentes períodos de seguimento clínico. Conclusĩes - A técnica de hemoirrodectomia por grampeamento propicia menor intensidade de dor e retorno mais precoce às atividades profissionais, quando comparada à hemoirrodectomia convencional. Entretanto, sua eficácia não foi determinada, uma vez que ainda não estão disponíveis estudos prospectivos e randomizados com grandes casuísticas e seguimentos a longo prazo.

DESCRITORES - Hemorróidas, cirurgia. Grampeadores cirúrgicos. 


\section{REFERENCES}

1. Birolini D, Ferreira EA, Rasslan S, Saad, R. Surgery in Brazil. Arch Surg 2002;137:352-8

2. Boccasanta P, Capretti PG, Venturi M, Cioffi U, Simone M, Salamina G, ContessiniAvesani E, Peracchia A. Randomised controlled trial between stapled circumferencial mucosectomy and conventional circular hemorrhoidectomy in advanced hemorrhoids with external mucosal prolapse. Am J Surg 2001;182:64-8.

3. Cheetham MJ, Mortensen NJ, Nystrom PO, Kamm MA, Phillips RK. Persistent pain and faecal urgency after stapled haemorrhoidectomy. Lancet 2000;356:730-3.

4. Cheetham MJ, Cohen CR, Kamm MA, Phillips RK. A randomised, controlled trial of diathermy hemorrhoidectomy vs. stapled hemorrhoidectomy in an intended day-care setting with longer-term follow-up. Dis Colon Rectum 2003;46:491-7.

5. Correa-Rovelo JM, Tellez O, Obregón L, Miranda-Gomez A, Moran S. Stapled rectal mucosectomy vs. closed hemorrhoidectomy: a randomized, clinical trial. Dis Colon Rectum 2002;45:1367-74.

6. Esser S, Khubchandani I, Rakhmanine M. Stapled hemorrhoidectomy with local anesthesia can be performed safely and cost-efficiently. Dis Colon Rectum 2004;47:1164-9.

7. Fazio VW. Early promise of stapling technique for haemorrhoidectomy. Lancet 2000;355:768-9.

8. Ganio E, Altomare DFI, Gabrielli F, Milito G, Canute S. Prospective randomized multicentre trial comparing stapled with open haemorrhoidectomy. Br J Surg 2001;88:669-74.

9. Hetzer FH, Demartines N, Handschin AE, Clavien PA. Stapled vs excision hemorroidectomy: long-term results of a prospective randomized trial. Arch Surg 2002;137:337-40.

10. Ho YH, Cheong WK, Tsang C, Ho J, Eu KW, Tang CL, Seown-Choen F. Stapled hemorrhoidectomy: cost and effectiveness. Randomized controlled trial including incontinence scoring, anorectal manometry, and endoanal ultrasound assessments at up three months. Dis Colon Rectum 2000;43:1666-75.

11. Kairaluoma M, Nuorva K, Kellokumpu I. Day-case stapled (circular) vs. diathermy hemorrhoidectomy: a randomized, controlled trial evaluating surgical and functional outcome. Dis Colon Rectum 2003;46:93-9

12. Khalil KH, O'Bichere A, Sellu D. Randomized clinical trial of sutured versus stapled closed haemorrhoidectomy. Br J Surg 2000;87:1352-5.

13. Kirsch JJ, Staude G, Herold A. The Longo and Milligan-Morgan hemorrhoidectomy A prospective comparative study of 300 patients. Chirurg 2001;72:180-5.

14. Komborozos VA, Skrekas GJ, Pissiotis CA. Rubber band ligation of symptomatic internal hemorrhoids: results of 500 cases. Dig Surg 2000;17:71-6.

15. Longo A. Treatment of hemorrhoids disease by reduction of mucosa and hemorrhoidal prolapse with a circular suturing device: a new procedure. In: Sixth World Congress of Endoscopic Surgery, Rome, Italy, Bolonha: Monduzzi; 1998. p.777-84

16. Mehigan BJ, Monson JR, Hartley JE. Stapling procedure for haemorrhoids versus MilliganMorgan haemorrhoidectomy: randomised controlled trial. Lancet 2000;355:782-85.
17. Molloy RG, Kingsmore D. Life threatening pelvic sepsis after stapled haemorrhoidectomy. Lancet 2000;355:810.

18. Nahas SC, Borba MR, Brochado MC, Marques CF, Nahas CS, Miotto-Neto B. Stapled hemorrhoidectomy for the treatment of hemorrhoids. Arq Gastroenterol 2003;40:35-9.

19. Palimento D, Picchio M, Attanasio U, Lombardi A, Bambini C, Renda A. Stapled and open hemorrhoidectomy: randomized controlled trial of early results. World J Surg 2003;27:203-7.

20. Peng BC, Jayne DG, Ho YH. Randomized trial of rubber band ligation vs. stapled hemorrhoidectomy for prolapsed piles. Dis Colon Rectum 2003;46:291-7.

21. Pernice LM, Batalucci B, Bencini L, Borri A, Catarzi S, Kröning K. Early and late (ten years) experience with circular stapled hemorrhoidectomy. Dis Colon Rectum 2001;44:836-41.

22. Pessaux P, Lermite E, Tuech JJ, Brehant O, Regenet N, Arnaud JP. Pelvic sepsis after stapled hemorrhoidectomy. J Am Coll Surg 2004;199:824-5.

23. Racalbuto A, Aliotta I, Corsaro G, Lanteri R, Di Cataldo A, Licata A. Hemorrhoidal stapler prolapsectomy vs. Milligan-Morgan hemorrhoidectomy: a long-term randomized trial. Int J Colorectal Dis 2004;19:239-44.

24. Ripetti V, Caricato M, Arullani A. Rectal perforation, retropneumoperitoneum and pneumomediastinum after stapling procedure for prolapse hemorrhoids: report of a case and subsequent considerations. Dis Colon Rectum 2002;45:268-70.

25. Rowsell M, Bello M, Hemingway DM. Circumferential mucosectomy (stapled haemorrhoidectomy) versus conventional haemorrhoidectomy: randomised controlled trial. Lancet 2000;355:779-81.

26. Singer MA, Cintron JR, Fleshman JW, Chaudhry V, Birnbaum EH, Read TE, Spitz JS Abcarian H. Early experience with stapled hemorrhoidectomy in the United States. Dis Colon Rectum 2002;45:360-7.

27. Sutherland LM, Burchard AK, Matsuda K, Sweeney JL, Bokey EL, Childs PA, Roberts AK, Waxman BP, Maddern GJ. A systematic review of stapled hemorrhoidectomy Arch Surg 2002;137:1395-406.

28. Wilson MS, Pope V, Doran HE, Fearn SJ, Brough WA. Objective comparison of stapled anopexy and open hemorrhoidectomy: a randomized, controlled trial. Dis Colon Rectum 2002;45:1437-44.

29. Wong LY, Jiang JK, Chang SC, Lin JK. Rectal perforation: a life-threatening complication of stapled hemorrhoidectomy: report of a case. Dis Colon Rectum 2003;46:116-7. 